\title{
4-Aminopyridine-induced Epileptiform Activity and a GABA-mediated Long-lasting Depolarization in the Rat Hippocampus
}

\author{
Paul Perreault and Massimo Avoli \\ Montreal Neurological Institute and Department of Neurology and Neurosurgery, McGill University, Montreal, Québec, \\ Canada $\mathrm{H} 3 \mathrm{~A}$ 2B4
}

\begin{abstract}
Two types of spontaneous field potentials were recorded in rat hippocampal slices after addition of 4-aminopyridine (4AP; $50 \mu \mathrm{M})$. One consisted of brief, epileptiform discharges that occurred at $0.6 \pm 0.2 \mathrm{sec}^{-1}$ in the CA3 and CA1 areas. The other type occurred less frequently $\left(0.036 \pm 0.013 \mathrm{sec}^{-1}\right)$ and was recorded in CA1, CA3, and dentate areas. It corresponded in all regions to an intracellular long-lasting depolarization (LLD; duration, 300-1200 msec; peak amplitude, 2-15 mV) that was abolished by bicuculline methiodide; therefore, it was mediated by $\mathrm{GABA}_{\mathrm{A}}$ receptors.

Sectioning experiments and the occurrence of propagation failures indicated that LLDs could be initiated by any area of the slice. Furthermore, the propagation of LLDs did not follow any consistent or predictable pattern along known anatomical hippocampal pathways. Finally, neither the occurrence nor the propagation of LLDs was affected when excitatory synaptic transmission was blocked by NMDA and non-NMDA receptor antagonists. In the presence of antagonists of glutamatergic receptors, LLDs disappeared after the omission of $\mathrm{Ca}^{2+}$ or the addition of $\mathrm{Cd}^{2+}$ to the perfusing solution, suggesting that synaptic transmission was required for their generation.

These data indicate that 4-AP discloses both interictal epileptiform discharges and LLDs in the rat hippocampus. The first type of activity is presumably related to certain properties of CA3 pyramidal neurons and the neuronal circuit, whereas LLDs originate from the spontaneous, periodic activity of GABAergic interneurons located in any area of the hippocampus, and can propagate to the other areas by the use of nonsynaptic mechanisms. We propose that 4-AP reveals a novel type of interaction among GABAergic interneurons that is based on the accumulation and the dispersion of $\mathrm{K}^{+}$.
\end{abstract}

Neuroscientists interested in the study of ion channels and synaptic transmission have, in recent years, paid considerable attention to aminopyridines, particularly 4-aminopyridine (4-AP) (for review, see Thesleff, 1980). 4-AP is also known to induce

Received Dec. 7, 1990; revised Aug. 1, 1991; accepted Aug. 14, 1991.

This work was supported by grants from the MRC of Canada (MA-8109), Hospital for Sick Children Foundation, and Savoy Foundation to M.A. P.P. was an MRC Fellow; M.A. is an FRSQ Scholar. We are grateful to Ms. Sue Schiller and Mr. Andrew Topaczewski for technical assistance, to Mr. V. Epp for clerical help, and to Dr. P. Gloor for reading an early draft.

Correspondence should be addressed to Dr. M. Avoli, Montreal Neurological Institute, 3801 University Street, Montreal, Québec, Canada H3A 2B4.

Copyright (C) 1992 Society for Neuroscience $0270-6474 / 92 / 120104-12 \$ 05.00 / 0$ seizures in humans after poisoning (Spyker et al., 1980) or during therapeutical trials of the drug (Thesleff, 1980). Thus, 4-AP causes electrographic seizures when applied on the neocortex (Szente and Baranyi, 1987) or tonic-clonic seizures when injected systemically (Mihaly et al., 1990). The epileptogenic effects of 4-AP have also been studied in the in vitro brain slice. Published reports indicate the presence of interictal epileptiform activity after 4-AP application to CA3 area hippocampal slices (Voskyul and Albus, 1985; Rutecki et al., 1987; Perreault and Avoli, 1991), although ictal discharges also occur in immature slices (Chestnut and Swann, 1988; Avoli, 1990). In the CA1 region, three studies have failed to record any 4-AP-induced epileptiform activity (Buckle and Haas, 1982; Segal, 1987; Perreault and Avoli, 1989), but two others have demonstrated the presence of epileptiform field discharges (Voskyul and Albus, 1985; Holsheimer and Lopes da Silva, 1989). The understanding of the effects induced by 4-AP on hippocampal slices is further complicated by reports describing other types of spontaneous potentials. In both CA1 and CA3 areas, Voskyul and Albus (1985) have recorded a type of spontaneous activity that occurred at a lower rate than the epileptiform discharges and did not depend on synaptic transmission. We have also observed a synchronous GABAergic potential in these two hippocampal areas during treatment with 4-AP (Perreault and Avoli, 1989, 1991). A similar GABAergic potential was recorded in neostriatal slices (Kita et al., 1985) as well as in rat (Aram et al., 1991) and human neocortical slices (Avoli et al., 1988) treated with 4-AP. Finally, when 4-AP was applied focally onto the CA1 area, spontaneous slow hyperpolarizations occurred at regular intervals (Segal, 1987).

In view of the different findings, we investigated the nature of the spontaneous activity induced by 4-AP in the CA1, CA3, and dentate areas of the rat hippocampal slice.

Some of these results have been reported in abstract form (Perreault and Avoli, 1987).

\section{Materlals and Methods}

Experiments were performed using hippocampal slices from male Sprague-Dawley rats (200-300 gm). The animals werc ancsthetized with ether and decapitated. The hippocampus was quickly dissected free and placed in artificial cerebrospinal fluid (ACSF). Transverse hippocampal slices (400-450 $\mu \mathrm{m}$ thick) were cut on a Mcllwain tissue chopper and transferred to a recording chamber where they were kept at $34-35^{\circ} \mathrm{C}$ on a filter paper at the interface between oxygenated ACSF and a humidified atmosphere saturated with $95 \% \mathrm{O}_{2}$ and $5 \% \mathrm{CO}_{2}$. The slices were perfused at a constant rate $(0.2-0.5 \mathrm{ml} / \mathrm{min})$ with oxygenated ACSF of the following composition (in $\mathrm{mM}$ ): $\mathrm{NaCl}, 124.0 ; \mathrm{KCl}, 2.0 ; \mathrm{KH}_{2} \mathrm{PO}_{4}, 1.25$; $\mathrm{MgSO}_{4}, 2.0 ; \mathrm{CaCl}_{2}, 2.0 ; \mathrm{NaHCO}_{3}, 26.0 ;$ and glucose, 10 . The ACSF was 
equilibrated with $95 \% \mathrm{O}_{2}$ and $5 \% \mathrm{CO}_{2}$ to a $\mathrm{pH}$ of 7.4. In some experiments, $\mathrm{Ca}^{2+}$ was omitted from the solution or $\mathrm{Cd}^{2+}(500 \mu \mathrm{M})$ was added in order to block synaptic transmission.

The slicing procedure employed in the experiments reported in this article was modified slightly from the protocol used in one of our previous studies (Perreault and Avoli, 1989). Since the 4-AP-induced epileptiform activity recorded in $\mathrm{CAl}$ by some investigators originated from the CA3 area (Voskyul and Albus, 1985), we postulated that the reason others (including ourselves) failed to observe this kind of epileptiform activity in the CA1 region could be related to a low viability of CA3 neurons, which might be injured by the slicing procedure. Therefore, in order to improve the viability of CA3 neurons, special precautions were taken during manipulations of the excised hippocampus to keep the alvear side underneath, facing the wet filter paper. The response properties of the $C \wedge 1$ neurons of slices obtained with the new protocol were apparently normal as assessed by monitoring the population spike evoked by stimulating the Schaffer collaterals of slices bathed in normal ACSF. However, in the presence of 4-AP $(50 \mu \mathrm{M})$, spontaneous interictal field activity in the CA1 area was seen in $87 \%$ of the slices $(n=36)$ obtained with the modified procedure. It is therefore likely that the overlying white matter of the alveus protects this region when slicing is done with the modified procedure.

Drug application. Drugs were applied either to the perfusing ACSF, or focally using a glass micropipette (5-10 $\mu \mathrm{m}$ tip diameter) filled with a known amount of drug dissolved in ACSF. 4-AP was added to the perfusing ACSF to achieve a final concentration of $50 \mu \mathrm{M}$. In some experiments, the following drugs were also added: 6-cyano-7-nitroquinoxaline-2,3-dione (CNQX; 1-20 $\mu \mathrm{M}$ ), 6,6-dinitroquinoxaline-2,3-dione (DNQX; 1-10 $\mu \mathrm{M}$ ), 3-3 (2-carboxy piperazinc-4-yl) propyl-1-phosphonate (CPP; 1-5 $\mu \mathrm{M}$ ), DL-2-amino-5-phosphonovalerate (APV; 10-100 $\mu \mathrm{M})$, bicuculline methiodide (BMI; 20-50 $\mu \mathrm{M}$ ), theophylline (300 $\mu \mathrm{M})$, atropine $(1 \mu \mathrm{M})$, propranolol $(10 \mu \mathrm{M})$, phentolamine $(10 \mu \mathrm{M})$, cimetidine $(20 \mu \mathrm{M})$, strychnine $(1 \mu \mathrm{M})$, and naloxone $(2 \mu \mathrm{M})$. In some cases, BMI $(50 \mu \mathrm{M})$ was applied focally. All chemicals were acquired from Sigma with the exception of CPP and CNQX, which were obtained from Tocris Neuramine, and phentolamine, which was obtained from Ciba Geigy.

Recording and stimulation. Electrodes for intracellular recordings were filled with $4 \mathrm{M}$ K-acetate (resistance, $40-70 \mathrm{M} \Omega$ ) or a mixture of $\mathrm{K}$-acetate (4 M) and 2(tri-methyl-amino)- $N$-(2,6-dimethylphenyl) acetamide (QX-314; $50 \mathrm{~mm}$; Astra), whereas for extracellular recordings, lower-impedance electrodes $(2-10 \mathrm{M} \Omega$ ) were filled with $2 \mathrm{M} \mathrm{NaCl}$. Intraand extracellular signals were fed to high-impedance amplifiers with a bridge circuit that allowed current to pass through the intraccllular recording electrode. The bridge was monitored carefully throughout the experiments and adjusted as necessary. Signals were displayed on a Gould chart recorder and oscilloscope and in some cases recorded on tape for later analysis. Intracellular recordings were obtained from pyramidal cells in the CA3b and CA1b regions as well as from dentate granule cells (Lorente de Nó, 1934). Extracellular activity was recorded by positioning the electrode in the stratum (s.) pyramidale of the CAlb, $\mathrm{CA} 3 \mathrm{~b}$, or CA $3 \mathrm{c}$ areas. In the dentate region, extracellular signals were recorded by positioning the electrode in the s. granulosum of the upper blade of the dentate area. Mossy fiber stimuli were delivered through bipolar stainless steel electrodes placed in the granule cell body layer or in the hilar region of the dentate area. Dentate granule cells were activated orthodromically by positioning the stimulating electrode on the subicular side of the hippocampal fissure, along the perforant path, whereas the electrode was placed in the CA1 s. radiatum to stimulate the Schaffer collaterals.

Sectioning experiments. A series of cutting experiments was carried out to establish the origin and the pathway(s) involved in the propagation of spontaneous activity induced by 4-AP in the hippocampal slice. A microknife was used for each cut in the area of interest. After cutting, a stimulating electrode was positioned on either side of the cut pathway to ensure that the section was complete and that the fibers remained functional. To confirm the accuracy of the section, the tissue on either side of the cut was also separated by a distance of 50-500 $\mu \mathrm{m}$.

The Schaffer collaterals were sectioned by cutting through the $\mathrm{s}$. radiatum along an axis perpendicular to the $\mathrm{s}$. pyramidale from $\mathrm{s}$. pyramidale to the edge of the s. lacunosum-moleculare. This cut was made at the level of the CA1c subarea to avoid the presence of any CA2-CA3a neurons on the subicular side of the cut. Sometimes the cut was enlarged from the alveus to the hippocampal fissure to isolate CA1 from CA3. The CA 3 area was isolated from the CA1 and the dentate regions by enlarging this cut from the hippocampal fissure to a junction point between the dentate gyrus and the hippocampus (part of the CA4 area therefore remained on the dentate side of the cut). Dentate and CA1 regions were separated by sectioning carefully along the fissure to make sure that the s. lacunosum-moleculare remained on the CA1 side. In other slices, the mossy fiber pathway was interrupted by sectioning the slice from the s. oriens to the hippocampal fissure along an axis perpendicular to the s. pyramidale to $\mathrm{CA} 3 \mathrm{c}$ area.

Time delay measurements. For these experiments, the extracellular signals were recorded simultaneously in all areas of the slice and displayed on a digital oscilloscope. For each trace, the onset of the 4-APinduced spontaneous potentials was determined as the time of the earliest deflection of the baseline recording. All quantitative results are expressed as mean $\pm \mathrm{SD}$. The results obtained were compared by using the Student's $t$ test and considered significantly different if $p<0.05$.

\section{Results}

\section{Spontaneous synchronous activity induced by 4-AP}

Bath application of 4-AP to hippocampal slices produced the appearance of two types of spontaneous field potential that could be discriminated by their shape and frequency of occurrence (Fig. 1B). One type was recorded simultaneously in the CA3 and $\mathrm{CA} 1$ areas and consisted of brief interictal-like epileptiform field potentials occurring at a frequency of $0.3-1.3 \mathrm{sec}^{-1}(0.6 \pm$ $0.2 \mathrm{sec}^{-1} ; n-31$ slices). In both regions, these spontaneous epileptiform discharges, when recorded in the s. pyramidale, consisted of $20-70 \mathrm{msec}$ positive waves with negative-going population spikes (Fig. $1 \mathrm{C}$ ). However, as shown in Figure 1, Ca and $C b$, the epileptiform events recorded in CA3 were more robust, as indicated by the greater number of population spikes (4-11 in CA3 as compared to 2-5 in CA1) and their higher amplitude ( $2 \pm 1.2 \mathrm{mV} ; n-4$ slices; range, $0.5-4 \mathrm{mV}$ in CA3) as compared to CAl bursts $(0.3 \pm 0.5 \mathrm{mV} ; n=10$ slices; $p<$ 0.05 ; range, $0.05-1.3 \mathrm{mV}$ ). The epileptiform activity in C.A1 was seen in $87 \%$ of the slices analyzed $(n=36)$, and in $19.3 \%$ of these cases consisted of a simple positive-going wave without any visible population spikes. Epileptiform activity in CA3 was more prominent in the CA3c subfield and was never observed in the dentate area ( $n=60$ slices).

The other type of spontaneous potential occurred at a lower rate $\left(0.036 \pm 0.013 \mathrm{sec}^{-1} ; n=23\right.$ slices; range, $\left.0.005-0.07 \mathrm{sec}^{-1}\right)$ and lasted longer (400-1000 $\mathrm{msec})$ than the brief interictal events. It was recorded simultaneously, with small delays, in all regions of the hippocampal slice (Fig. $1 B$ ). Furthermore, as shown in Figure $1 B$, there was a significant refractory effect of this potential on the interictal activity as indicated by the $1.9-6.4 \times$ longer interdischarge interval following the occurrence of this potential $(2.9 \pm 1.7 \times$ longer; $n-6$ slices). When recorded in the cell body layer of CAl or dentate gyrus, the second type of activity appeared as a smooth, positive-going potential, whereas in the pyramidal layer of CA3 there was usually a faster, negative-going deflection preceding a smoother and low-amplitude positive-going wave. At times, this second type of potential could be preceded by an epileptiform event that, however, was of larger amplitude in the CA1 subfield than in CA3 (see expanded traces in Fig. $1 C c, C d$, as well as in the top panel in Fig. $6 A$ ). Other times the long-lasting spontaneous potential was preceded by a brief positive wave reminiscent of a field EPSP (see extracellular recording traces in Figs. $2 A, 3 A$ ).

\section{Effects of 4-AP on CA3 neurons}

Simultaneous intra- and extracellular recordings revealed that the interictal epileptiform field discharges in the $s$. pyramidale of the CA3 region corresponded to brief depolarizations of the neuronal membrane with overriding fast action potentials (Fig. 

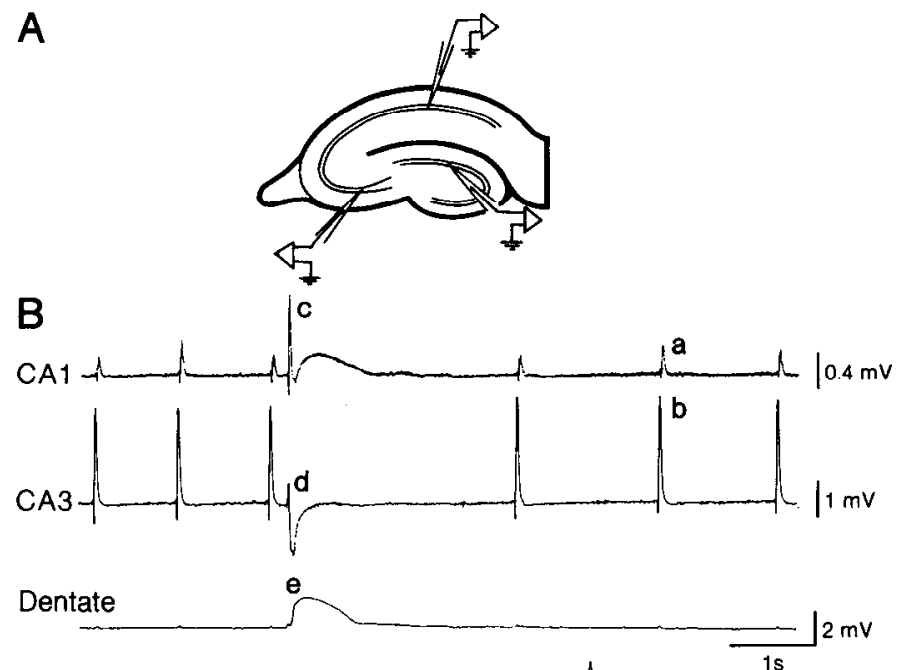

C
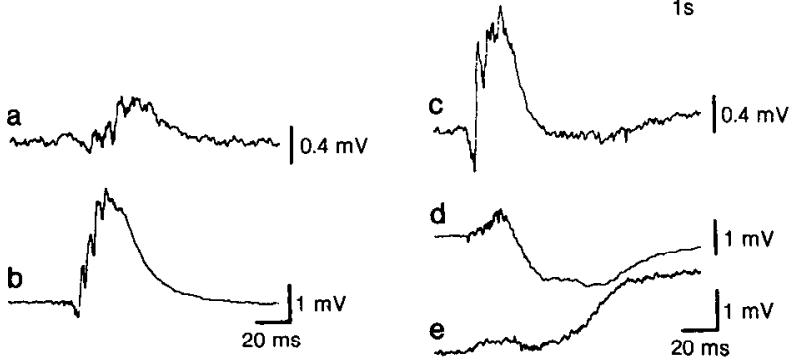

Figure 1. Spontaneous field activity induced by 4-AP. A, Diagram of the hippocampus showing the position of the recording electrodes in $\mathrm{CA} 1, \mathrm{CA} 3$, and dentate areas where the signals shown in $B$ and $C$ were recorded. $B$, Simultaneous field recordings showing the two types of spontaneous activity produced by $4-\mathrm{AP}$ in $C A 1, C A 3$, and dentate regions (Dentate). Interictal bursts in $\mathrm{CA} 1$ and $\mathrm{CA} 3$ areas occurred at regular intervals, whereas a less frequent, slower positive wave was recorded in all regions. $C, a$ and $b$ show one example of interictal bursts occurring in $\mathrm{CA} 1$ and $\mathrm{CA} 3$, respectively, and displayed at a shorter time base for clarity (see labeling in $B$ ); $c-e$ are expanded traces that show the onset of the slow potential that occurred in CA1, CA3, and dentate areas, respectively (see labeling in $B$ ).

$2 A$ ). This intracellular activity was reminiscent of the paroxysmal depolarization shift produced by several convulsant drugs (for review, see Alger, 1984). The second type of field potential disclosed by 4-AP coincided with a $2-12 \mathrm{mV}(8.8 \pm 2.6 \mathrm{mV}$; $n=10$ cells) depolarization of the neuron's membrane that lasted $350-1200 \mathrm{msec}(548 \pm 230 \mathrm{msec} ; n=14$ cells) and was followed by a hyperpolarization (amplitude: $6.5 \pm 1.8 \mathrm{mV}$; range, $5-10 \mathrm{mV} ; n=10$ cells; duration: $1440 \pm 598$; range, 500-2000 msec; $n=10$ cells). It resembled the long-lasting depolarization (LLD) previously reported by us in CA1 pyramidal cells, where it is caused by the activation of $\mathrm{GABA}_{\mathrm{A}}$ receptors located on the dendrites of pyramidal cells (Perreault and Avoli, 1989). This was also confirmed in the CA3 subfield by applying BMI focally onto the apical dendritic area of pyramidal cells. As shown in Figure $2 B$, BMI reversibly blocked the slow depolarization, thereby uncovering a hyperpolarizing potential $(n=4)$.

As in CA1, the onset of the LLDs recorded intra- or extracellularly in CA3 displayed great variability. However, in most cases they were preceded by a burst of action potentials (Fig. $2 C$, top trace) or a small depolarization that corresponded presumably to an EPSP (Fig. $2 A$, top trace). In $\approx 5 \%$ of the cases (e.g., Fig. 2C, bottom trace), LLDs were initiated by a brief hyperpolarization of the membrane, presumably an IPSP. In the latter case, action potentials occurred near the peak of the IPSP and on the initial part of the rising phase of the LLD. These action potentials were recorded in more than $50 \%$ of the CA3 neurons $(n=7)$ and had features similar to the action potentials associated with the LLDs recorded in CA1, including varying amplitudes, IS-SD fractionation, and insensitivity to membrane hyperpolarization (Perreault and Avoli, 1989). A small and fast-rising brief depolarization reminiscent of an EPSP was sometimes observed near the LLD onset (Fig. $2 C$, arrow on top trace).

Stimulation of the mossy fibers evoked a burst followed by an LLD (Fig. 2D). However, when the stimulation was applied too frequently or shortly after the occurrence of a spontaneous LLD $(<2-5 \mathrm{sec})$, an additional LLD could not be evoked. Stimulations applied at slightly longer intervals $(>3-15 \mathrm{sec}$ ) evoked LLDs of lower amplitude and duration. LLDs were therefore followed by an absolute and a relative refractory period. This property was not shared by the epileptiform bursts that could follow afferent fiber stimulations given at short intervals $(<1$ sec). LLDs were also evoked in CA3 neurons by stimulating anywhere in the slice.

\section{Effects of 4-AP on CA1 neurons}

The effects induced by 4-AP on CA1 neurons have been reported in a previous publication (Perreault and Avoli, 1989). However, the modified slicing procedure used for the present experiments (see Materials and Methods) prompted us to reinvestigate the effects induced by 4-AP in this region. As shown in Figure $3 A$, the brief interictal events recorded extracellularly in the CA1b area (bottom trace) were correlated intracellularly (top trace) with FPSPs $(1.5-11 \mathrm{mV})$ that lasted up to $80 \mathrm{msec}$, and/or EPSP-IPSP sequences. Field discharges were correlated with intracellular bursts of action potentials in only 1 out of 24 neurons impaled from 24 different slices. In addition, LLDs similar to those observed in CA3 were also observed in the CA1 area. Compared to our previously published data (Perreault and Avoli, 1989), one difference here was that in $72 \%$ of the slices $(n=$ 18) many spontaneous LLDs ( $>50 \%$ ) were triggered by a field epileptiform discharge. This finding was probably related to the improved viability of CA3 neurons in the experiments reported here (see Materials and Methods). However, in agreement with our previous study, in $80 \%$ of the slices $(n=12)$, the response to orthodromic stimulations consisted of a single population spike. Even with high-intensity stimuli, additional population spikes or bursts failed to occur (Fig. 3B). However, a small burst similar to the spontaneously occurring potential could be induced by stimulating the Schaffer collaterals with a low-intensity $(10-50 \mu \mathrm{A}$ ), brief train (three to five stimuli at $150-250 \mathrm{~Hz}$ ) that mimicked presumably the excitatory input coming from CA3 (Fig. 3Cb).

The CA3 origin of CA1 bursts was also suggested by the fact that CA 3 bursts preceded those in CA1 by $8-24 \mathrm{msec}$ depending on electrode location ( $n=5$ slices; Fig. $3 D$, left). This latency corresponded to a propagation velocity of $0.2-0.4 \mathrm{~m} / \mathrm{sec}$, which is within the expected range for activity propagating along the Schaffer collaterals (Andersen et al., 1978). This interpretation was confirmed in experiments where a cut was made between CA1 and CA3 ( $n=8$ slices). The sectioning of the Schaffer collaterals abolished in CA1 both the interictal discharges and the discharges that preceded spontaneous LLDs (see Figs. $3 D$, 


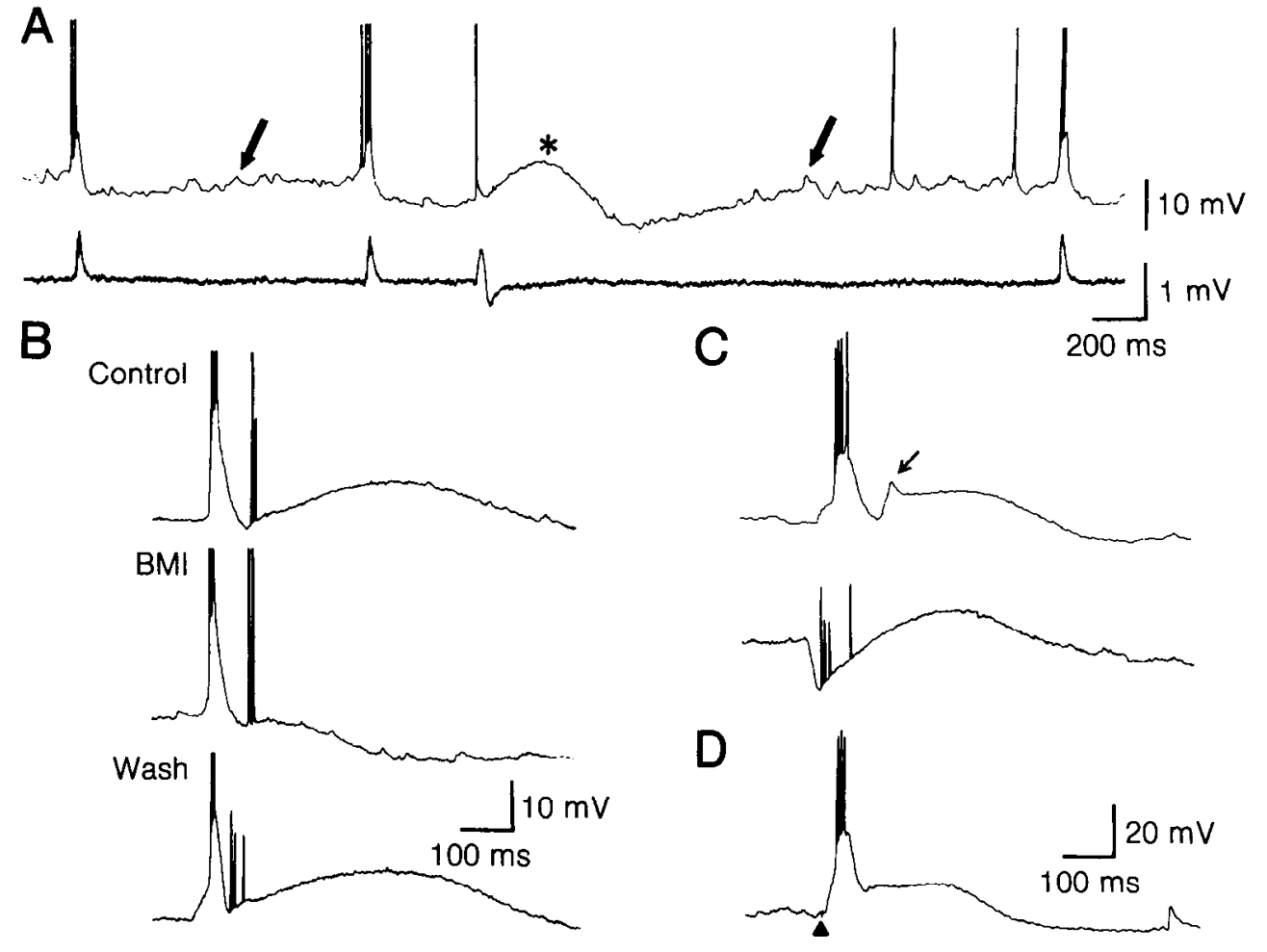

Figure 2. Spontaneous bursts and LLDs produced by 4-AP in CA3 neurons. $A$, Simultaneous intracellular (top trace) and extracellular (bottom trace) recordings obtained from the $\mathrm{s}$. pyramidale of the $\mathrm{CA} 3 \mathrm{c}$ area. Intracellular bursts were correlated with the interictal field events, whereas an LLD (asterisk on top trace) corresponded to the other multiphasic cvent. Arrows point to two low-amplitude, spontaneous PSPs. $B$, Focal application of BMI (50 $\mu \mathrm{M})$ onto the dendrites of a CA3 neuron blocked the spontaneously occurring LLD, indicating that it was mediated by $\mathrm{GABA}_{\mathrm{A}}$ receptors. $C$, Two examples of spontaneous LLDs taken from the same neuron showing the variability in LLD onset. In the top trace, the LLD was initiated by a burst followed by an EPSP (arrow), whereas the LLD shown in the bottom trace started as an IPSP associated with low-amplitude action potentials. $D$, Mossy fiber (triangle) stimulations evoked responses similar to those that occurred spontaneously (same neuron as in $C$ ). Action potentials are cut in $A$ and $B$. Calibrations in $D$ apply to $C$. Resting membrane potential of the cell in $A$ was not available; $B-D,-70 \mathrm{mV}$.
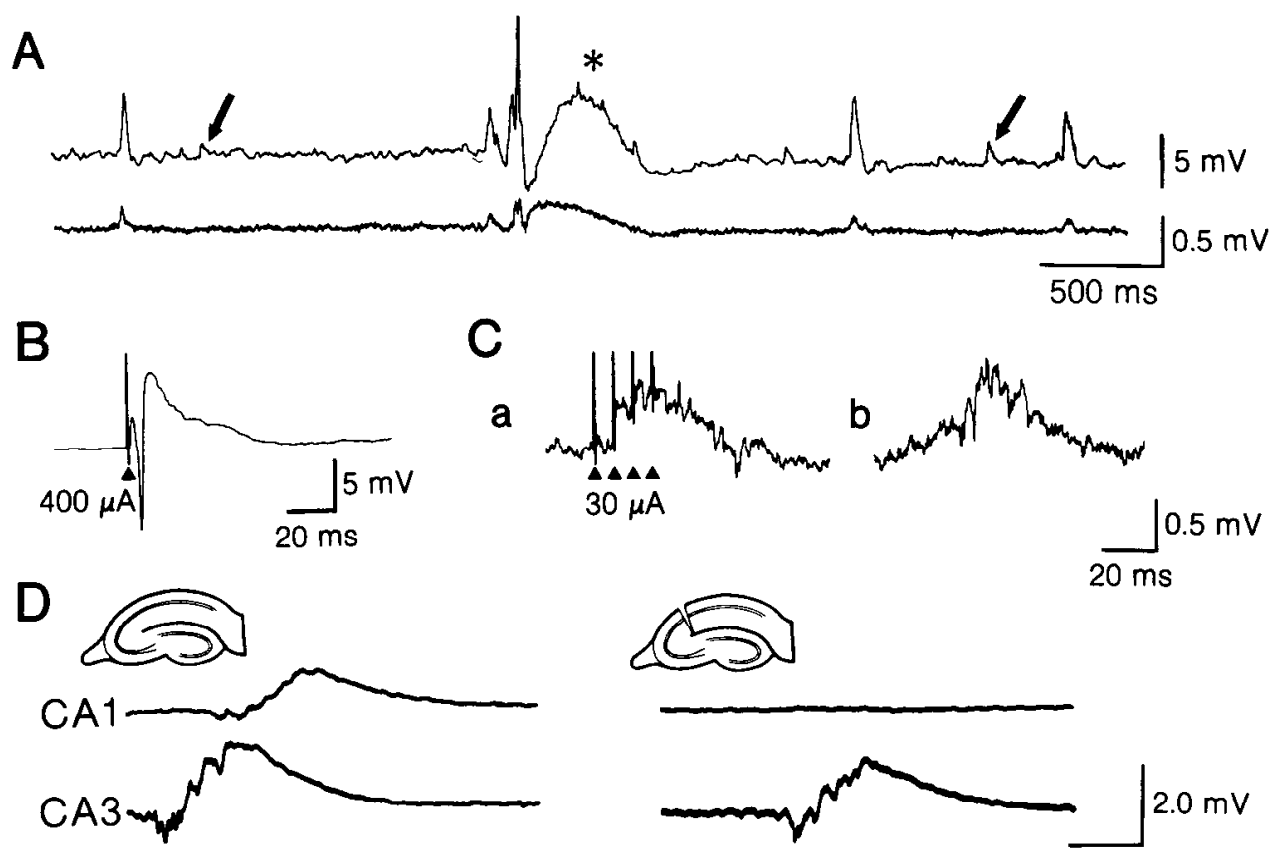

Figure 3. Spontaneous bursts and LLDs produced by 4-AP in CAl pyramidal neurons. $A$, Simultaneous intracellular (top trace) and extracellular (bottom trace) recordings obtained from the s. pyramidale of CAlb. Brief extracellular interictal events were correlated with short-lasting depolarizations (presumably EPSPs), whereas an LLD (asterisk on top trace) occurred during the slow field potential. Arrows point to two low-amplitude, spontaneous PSPs. $B$, The extracellular response obtained in the presence of 4-AP in the CA1 s. pyramidale after high-intensity ( $400 \mu \mathrm{A})$ stimulation of the Schaffer collaterals consisted of a singlc population spikc. $\mathrm{Ca}$. In the same slice as in $B$, a brief train of low-intensity stimulation of the Schaffer collaterals $(30 \mu \mathrm{A})$ evoked a small burst $(a)$ that was very similar to the one that occurred spontaneously $(b)$. $D$, The traces on the left show interictal bursts recorded simultaneously in the s. pyramidale of CA1b and CA $3 \mathrm{c}$ on an intact slice. Following a cut from the alveus to the fissure, this activity disappeared in CA1 but remained in CA3. The action potential riding on the EPSP at the onset of the LLD in $A$ was cut. Resting membrane potential of the neuron in $A$ was $-60 \mathrm{mV}$. 


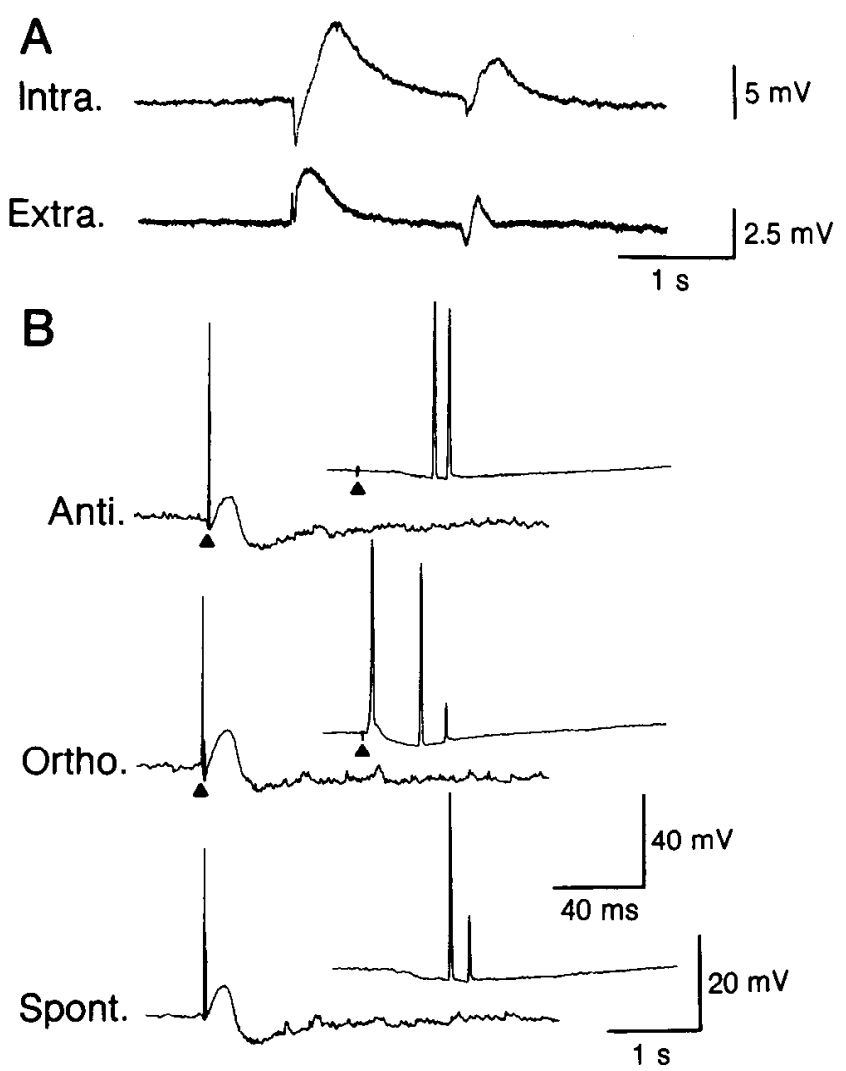

Figure 4. Spontaneous and evoked LLDs evoked by 4-AP in dentate granule cells. $A$, Simultaneous intracellular (Intra.) and extracellular (Extra.) recordings obtained from the s. granulosum of the dentate area showing the spontaneous occurrence of a doublet of LLDs. $B$, Examples of responses obtained in another dentate granule neuron after stimulation (triangles) of the mossy fibers (Anti.) and the perforant path (Ortho.). Note the similarities with the spontaneously occurring potential (Spont.). The insets show the presence of late action potentials in each case. Action potentials are cut in the traces shown in $B$ at slow time base. Resting membrane potential of the neuron in $A$ was $-61 \mathrm{mV}$; in $B$, not available.

6). Therefore the epileptiform activity produced by $4-\mathrm{AP}$ in the CA1 area originates in CA3.

\section{Effects of 4-AP on dentate neurons}

Simultancous intra- and extracellular field recordings obtained from the s. granulosum revealed that the spontaneous, positivegoing deflection on the extracellular record corresponded to a brief hyperpolarization followed by an LLD lasting 400-900 msec (Fig. 4A). The peak amplitude of the LLD measured 5$15 \mathrm{mV}(n=9)$ and was correlated with the decaying phase of the slow positive wave on the extracellular record, whereas the hyperpolarization was better correlated with the brief positive wave of the extracellular record. In about $5 \%$ of the slices ( $n=$ 60 ), LLDs appeared in doublets (Fig. $4 A$ ) or were followed by a series of 3-15 decrementing depolarizations separated by an $\approx 1 \mathrm{sec}$ interval. LLDs recorded in dentate neurons were initiated by an IPSP and were followed by a 0.9-5.0 sec hyperpolarization ( $n=8$ cells). The GABAergic nature of the LLD seen in this region was confirmed by BMI application $(20 \mu \mathrm{M})$, which abolished the early IPSP and the LLD ( $n=2$; not illustrated). Similar LLDs were evoked by stimulating the mossy fibers (Fig. $4 B$, Anti.) or any other part of the slice. Perforant path stimulations evoked an EPSP that preceded the entire sequence of potentials (Fig. $4 B$, Ortho.). In $44 \%$ of the cases ( $n=72$, eight cells), action potentials of varying amplitudes occurred during spontaneous or evoked LLDs and displayed features identical to those described for the CA3 and CA1 regions (insets in Fig. $4 B)$.

\section{4-AP and spontaneous synaptic potentials}

In addition to the two types of synchronous activity described above, 4-AP also induced the appearance of low-amplitude spontaneous postsynaptic potentials (PSPs) that increased the baseline noise of the intracellular recordings (see arrows in the intracellular traces in Figs. $2 A, 3 A$ ). However, the nature and expression of this spontaneous synaptic activity differed from one region to another. The traces in Figure 5 show typical examples of PSPs elicited by 4-AP in neurons of the CA3, CA1, and dentate areas. These recordings indicate that this activity had greater amplitude in CA3 cells than in CA1 neurons. Furthermore, these PSPs were virtually absent in dentate neurons. This difference is also illustrated in the histograms of Figure 5, which show the frequency distribution of PSPs of different amplitude in 10 neurons impaled in the CA3, CA1, and the dentate regions. These results demonstrate, therefore, a correlation between the propensity of a given area to produce epileptiform discharges and the occurrence and amplitude of PSPs, the order being $\mathrm{CA} 3>\mathrm{CA} 1>$ dentate.

\section{Origin and propagation of $L L D s$}

To understand better the origin of the LLDs, we performed a series of sectioning experiments in which fiber pathways were severed and some areas of the slices were isolated. One typical example of the results obtained in 12 slices is shown in Figure $6 \mathrm{~A}$. The top panel shows the two types of spontaneous activity produced by 4-AP in the intact slice where field potentials were recorded simultaneously in $\mathrm{CA} 3, \mathrm{CA} 1$, and dentate gyrus. When the slice was cut between CA1 and CA3 (Fig. 6A, second panel), all epileptiform activity was abolished in the CA1 area but remained present in CA3. However, spontaneous LLDs continued to appear simultaneously, with brief delay, in all areas of the slice after this procedure. Spontaneous LLDs and bursts persisted in the CA3 area when this region was completely isolated from the remainder of the slice (third panel). Under these conditions, LLDs were still recorded nearly simultaneously in both the CAl and the dentate regions. Further dissection along the fissure to isolate completely CAl and the dentate gyrus demonstrated that LLDs could be generated independently by each isolated area (Fig. 6A, bottom panel). The effects of these cuts on the frequency of occurrence of the LLDs recorded in $\mathrm{CA} 3, \mathrm{CA} 1$, and dentate regions are shown graphically in Figure $6 B$. Compared to the values obtained from intact slices, the LLD rate in CA3 was not significantly changed after all sections had been studied. However, the LLD rate in CA1 and dentate was depressed after the isolation of the CA3 region and decreased further in both regions after they had been isolated from each other $(p<0.01)$. In four other slices, we found that the mossy fibers were not required for LLD propagation between $\mathrm{CA} 3$ and the dentate gyrus because this activity could spread in both areas after sectioning this pathway (not shown). These results therefore failed to identify any specific pacemaker region or any obligatory LLD propagation pathway and raised the possibility that this potential could be initiated in any of the hippocampal regions. This was confirmed in experiments in which we observed propagation failures. While recording simulta- 

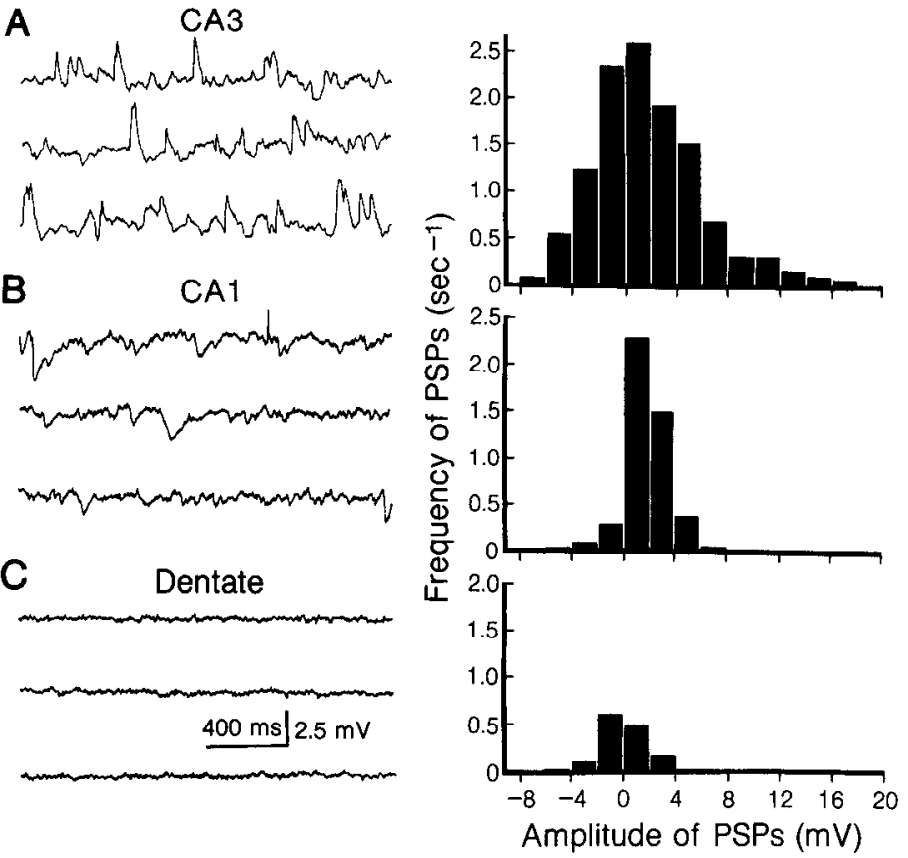

Figure 5. Spontaneous synaptic potentials recorded intracellularly in CA3 and CA1 pyramidal cells and dentate granule cells in the presence of 4-AP. The traces on the left show the small spontaneous potentials that occurred in one neuron of the CA3c $(A), \mathrm{CAlb}(B)$, and dentate areas $(C)$. The corresponding histograms on the right show the frequency distribution of spontaneous synaptic potentials of different amplitudes recorded in 10 different neurons impaled in each region and taken from 10 different slices. For each cell, the frequency distribution of the synaptic potentials was calculated for a period of $100 \mathrm{sec}$. Rest $V_{m}$ of the neuron in $A$ was $-61 \mathrm{mV} ; B,-67 \mathrm{mV}$; and $C,-59 \mathrm{mV}$.

neously in CA1 and CA3, we observed in five slices LLDs in CA3 that failed to propagate to CA1, and in six other slices we noted LLDs occurring in CA1 without any corresponding potential in CA3 (not shown).

The origin of LLDs was further investigated in eight slices by measuring the delay between the onset of the LLDs recorded simultaneously in the cell body layer of CA3, CA1, and dentate areas. These results confirmed that there was no single area of origin for this type of activity. In $39.6 \%$ of the cases $(n=56)$, spontaneous LLDs were recorded first in CA3, while $31 \%$ of them started in CAl and $2 \%$ in the dentate area. Moreover, about $17 \%$ of the spontaneous LLDs appeared first, with no measurable delay, in both CA3 and dentate or in both CA1 and dentate. Finally, in $10.4 \%$ of the cases, LLDs appeared in all three areas with no measurable delay between any of the three regions. Delays of propagation could be underestimated in these experiments if spontaneous potentials originated somewhere between the three recorded sites and propagated simultaneously toward two or all of them. This may have been the case when no delay was observed between regions.

In any given slice, LLDs invaded the different areas of the slice by following several patterns. For instance, although the activity originating in CA1 usually propagated first to CA3 and then to dentate, in the case of seven events the dentate area was invaded before CA3, while five other LLDs invaded simultaneously CA 3 and dentate areas. When slices were cut between CA1 and CA3 from the alveus to the fissure, the most frequently found pattern of propagation (62\% of the cases; $n=14$ events)
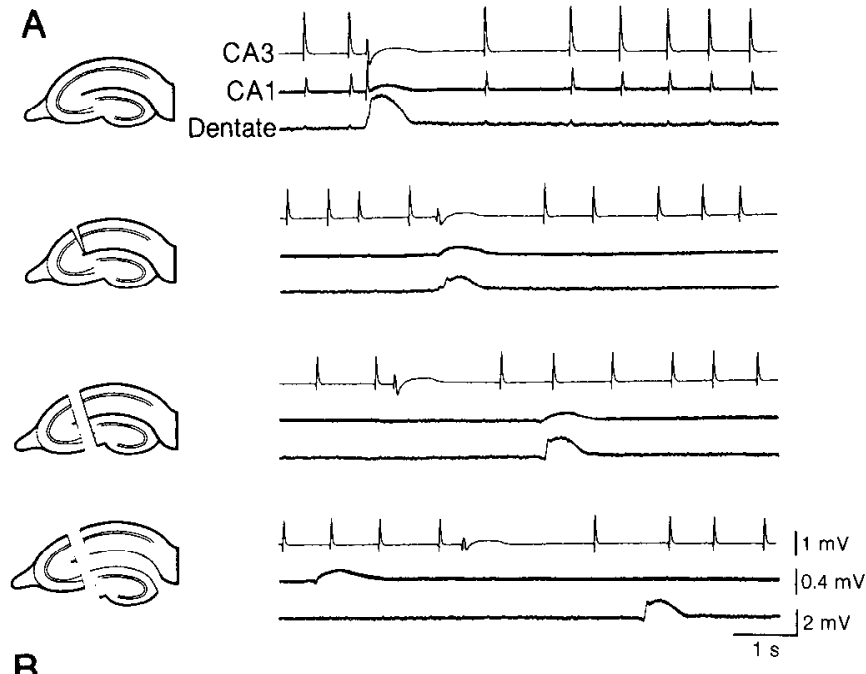

B

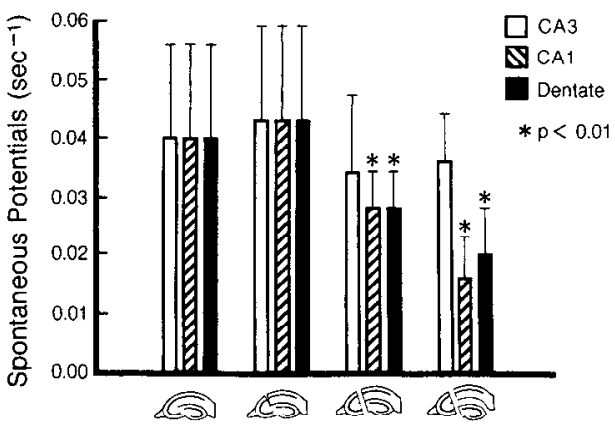

Figure 6. Effects of sections of fiber pathways on the propagation of bursts and LLDs. $A$, The top panel shows the spontaneous LLDs and bursts recorded simultaneously in the s. pyramidale of CA3c (top trace) and $\mathrm{CAlb}$ areas (middle trace) and in the s. granulosum of the dentate region (bottom trace) in an intact slice exposed to 4-AP. LLDs remained coupled in all regions after sectioning the fibers between CAl and CA3 (second panel) and appeared simultaneously in CA1 and dentate after the CA3 area had been severed from the rest of the slice (third panel). LLDs could be generated by each isolated region of the hippocampus (bottom panel). B. Histogram displaying the effects of these cuts on the frequency of occurrence of the LLDs recorded in each area.

consisted of LLDs originating from CA 3 and invading both CA1 and dentate areas simultaneously, with no measurable delay between the two. In this situation, however, compared to the intact slice, the time delay increased between CA3-dentate (from $14.3 \pm 14 \mathrm{msec}, n=54$ events, in control to $51.7 \pm 21.7 \mathrm{msec}$, $n=24$, after the cut; $p<0.01$ ) and CA3-CA1 (from $14.3 \pm$ $17.4, n=52$ events, to $65.4 \pm 26.6 \mathrm{msec}, n=19 ; p<0.01$ ). Less often, LLDs were initiated in CA1 (21\% of cases) and dentate ( $8 \%$ of cases) regions. LLDs recorded simultaneously in CA1 and dentate gyrus after complete separation from CA3 were initiated first in dentate gyrus in $90 \%$ of the cases analyzed, with time delays ranging from 50 to $207 \mathrm{msec}$ (101.7 \pm 57.3 msec; $n=11$ events; $p<0.01$ compared to intact slice). Stimulation of the s. radiatum in CAl evoked an LLD in dentate gyrus after a similar latency of $50-115 \mathrm{msec}(88.8 \pm 19.0 \mathrm{msec}$; $n=13$ ). These values would correspond to a propagation velocity of $0.004-0.017 \mathrm{~m} / \mathrm{sec}$, assuming direct propagation from one recording point to the other.

The difficulty estimating LLD velocity was compounded by the uncertainty of both the delay measurements (LLD origin could not be determined precisely) and the distance values (propagation pathways not clearly identified by the sectioning 
A

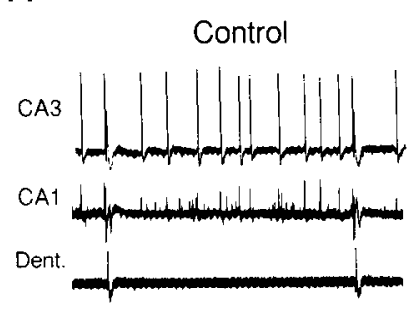

Figure 7. Excitatory amino acid antagonists fail to prevent the occurrence and the propagation of LLDs. $A$, Control traces (top) show a low-speed chart record of the spontaneous activity recorded extracellularly in the s. pyramidale of $\mathrm{CA} 1 \mathrm{~b}$ and $\mathrm{CA} 3 \mathrm{c}$ and the $\mathrm{s}$. granulosum of the dentate area. After the addition of $10 \mu \mathrm{M}$ DNQX (middle panel), or $10 \mu \mathrm{M}$ DNQX and $5 \mu \mathrm{M}$ CPP (bottom panel), LLDs were still recorded nearly simultaneously in all three regions. $B$, Plot of population spike amplitude measured in the CA1 s. pyramidale versus stimulation intensity of the Schaffer collaterals obtained in control condition (open circles), and after the addition of different doses of CNQX. $C$, Relationship between the frequency of occurrence of the LLDs and the concentration of CNQX added to the ACSF. These results were taken from the same slice as in $B$.
B

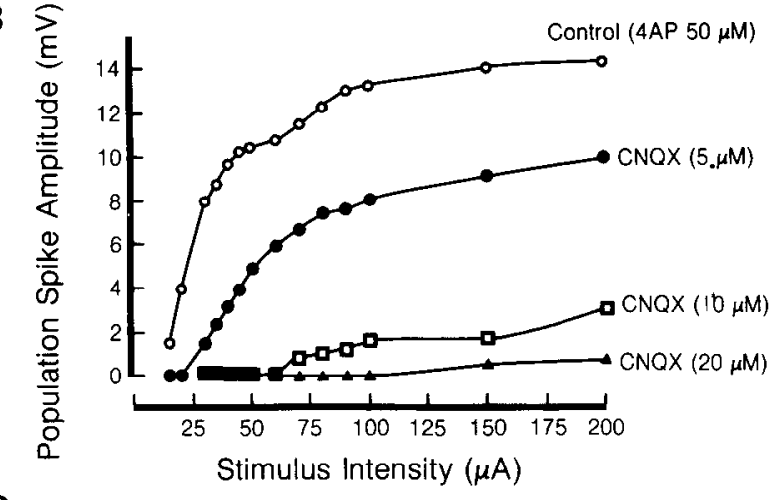

\section{$\mathrm{C}$}

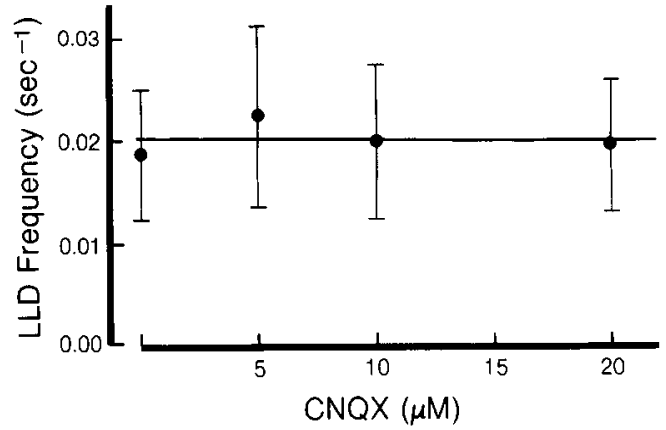

experiments). For comparison purposes, however, we computed the propagation velocity of LLDs spreading from CA 3 to CA1, assuming they were conducted directly from one area to the other, and thus we excluded all cases where no delay was observed. Under these conditions, the mean propagation delay measured corresponded to a velocity of $0.26 \pm 0.21 \mathrm{~m} / \mathrm{sec}$ (range, $0.1-1.25 \mathrm{~m} / \mathrm{sec} ; n=38$ ), which is close to the lower limit of what would be expected for conducting activity along the Schaffer collaterals (Andersen et al., 1978; Holsheimer and Lopes da Silva, 1989).

\section{Pharmacological analysis of spontaneous LLDS}

After the addition of DNQX or CNQX (3-10 $\mu \mathrm{m})$, which are antagonists of $\alpha$-amino-3-hydroxy-5-methyl-4-isoxazole propionic acid (AMPA)/kainate receptors (Honoré et al., 1988), the epileptiform activity in CA 3 and CA1 was abolished but LLDs continued to occur simultaneously in all three regions $(n=10$ slices; Fig. $7 A$, middle panel). The occurrence of LLDs was also not affected when NMDA receptor antagonists APV (20-100 $\mu \mathrm{M})$ or CPP (1-5 $\mu \mathrm{M})$ were added to the perfusing medium that already contained CNQX or DNQX ( $n=16$ slices; Fig. $7 A$, bottom panel). As both NMDA and non-NMDA receptor antagonists should completely block synaptic transmissions at synapses that utilize excitatory amino acids as neurotransmitters (Neumann et al., 1988; Davies and Collingridge, 1989; Lambert et al., 1989), these results indicated that LLD propagation in the hippocampus did not require excitatory amino acid-dependent synaptic transmission. This was confirmed by monitoring simultaneously the occurrence of spontaneous LLDs and the amplitude of the population spike recorded in the CA1 s. pyramidale in response to Schaffer collateral stimulation. When excitatory synaptic transmission in CA1 was completely blocked by high concentrations of CNQX (15-20 $\mu \mathrm{M}$; Fig. 7B), the LLD occurrence rate in the slice remained unchanged (Fig. $7 C$ ). However, though LLD occurrence was still coupled in all regions after CNQX application, the propagation delay increased significantly. In five slices, the mean delay between $\mathrm{CA} 1$ and CA3 increased, from a control value of $13.2 \pm 10.9 \mathrm{msec}(n=38$ LIDs) to $59.8+25.5 \mathrm{msec}$ (range, $15-125 \mathrm{msec} ; n=30$ LLDs; $p<0.01)$ in CNQX. The latter was very similar to the value obtained after cutting the Schaffer collaterals and would correspond to an apparent propagation velocity of $0.02-0.2 \mathrm{~m} / \mathrm{sec}$.

As illustrated in Figure 8, CNQX and CPP altered the shape of the LLDs by blocking the epileptiform discharge that preceded the LLDs in both CA1 and CA3 ( $n=10$ experiments). The sharp negative deflection at LLD onset in CA3 was also reduced under these conditions, such that LLD shape in CA1 and CA3 became almost identical (Fig. $8 A$ ). The intracellular correlate of these effects is demonstrated in Figure $8 B$, which illustrates LLDs recorded in a CA3 neuron impaled with a QX314-filled microelectrode to prevent action potential generation: although CPP $(2.5 \mu \mathrm{M})$ did not produce any significant effect on the spontaneous LLD, CNQX ( 3 or $9 \mu \mathrm{M}$ ) completely blocked the initial high-amplitude EPSP ( $n=10$ cells). Spontaneous I.L.Ds recorded from both CA 1 and CA 3 pyramidal cells in the presence of CNQX were initiated by an early IPSP and, in $\approx 20 \%$ of the cases, were followed by a late hyperpolarization. The occurrence of variable-amplitude action potentials associated with the LLDs was not affected by excitatory amino acid antagonists. These results therefore suggest that, even though fiber pathways utilizing non-NMDA receptors may participate in the generation of LLDs, they are by no means necessary. As no EPSP could be detected in those experiments, not even by hyperpolarizing the neuron membrane, it is likely, rather, that LLD generation was involving only the activity of GABAergic interneurons.

The mechanisms underlying the propagation of LLDs from one hippocampal area to another were further studied by omitting $\mathrm{Ca}^{2+}$ from the ACSF $(n=5)$ and by adding $\operatorname{Cd}^{2+}(n=1)$ to the medium in order to block $\mathrm{Ca}^{2+}$ entry through voltage-sen- 


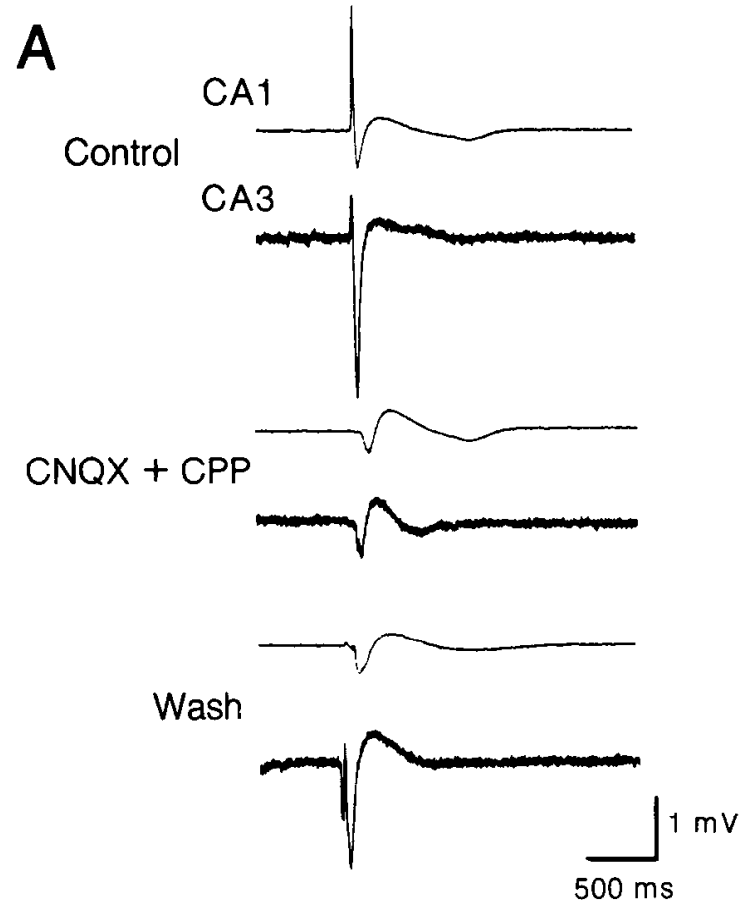

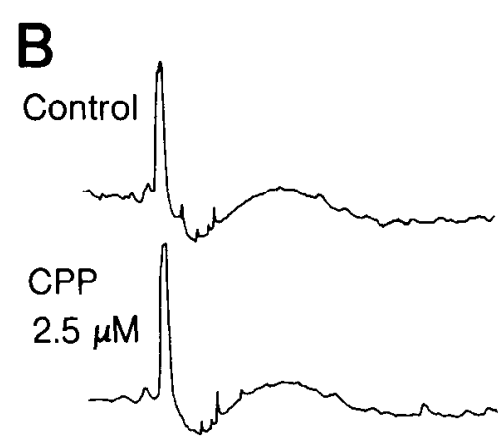

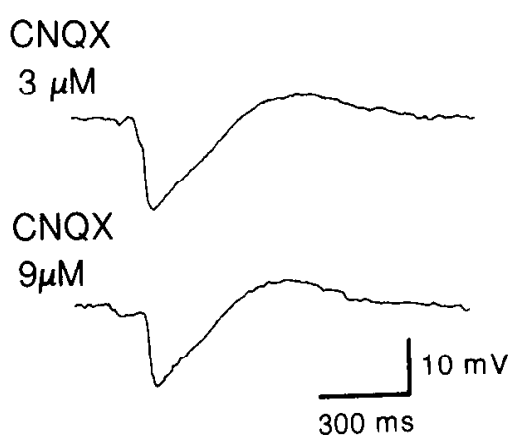

Figure 8. LLDs recorded intracellularly and extracellularly after the addition of excitatory amino acid antagonists. $A$, LLDs recorded simultaneously in the s. pyramidale of CAlb and $\mathrm{CA} 3 \mathrm{c}$ showing the blockage by CNQX $(15 \mu \mathrm{M})$ and CPP $(5 \mu \mathrm{M})$ of its initial part (middle traces). Note also the longer delay between the CAl and CA3 LLDs under those conditions. The effects of the antagonists were only partially eliminated by washing. $B$, Spontaneous LLDs recorded in a CA3c neuron impaled with QX-314-filled microelectrodes to block the action potentials associated with the initial bursts. Although CPP $(2.5 \mu \mathrm{M})$ did not affect LLD shape, CNQX ( 3 and $9 \mu \mathrm{M}$ ) blocked the initial burst. LLDs recorded under these circumstances started as an IPSP. Resting membrane potential of the cell in $B$ was $-55 \mathrm{mV}$. sitive $\mathrm{Ca}^{2+}$ channels. The top panel in Figure $9 A$ shows spontaneous LLDs recorded simultaneously in CA1 and CA 3 during perfusion with ACSF that contained 4-AP as well as CNQX (20 $\mu \mathrm{M})$ and $\mathrm{CPP}(5 \mu \mathrm{M})$. When $\mathrm{Ca}^{2+}$ was omitted from the perfusing solution, LLDs were completely blocked (Fig. $9 A$, middle panel) and reappeared after $\mathrm{Ca}^{2+}$ reintroduction (Fig. $9 A$, bottom panel), indicating that synaptic transmission was required for LLD generation. Moreover, when GABAergic synapses were blocked by adding BMI (30-60 $\mu \mathrm{M})$ to the ACSF already containing 4-AP, CNQX, and CPP, all activity was suppressed (Fig. $9 B ; n=5$ ). This finding implies that the only synchronous activity occurring when excitatory amino acid receptors are blocked was the GABAmediated LLDs recorded in pyramidal neurons and granule cells. In two slices, however, a spontaneous low-amplitude, negative-going potential (when recorded at the cell body layer) remained after BMI application (not shown). The shape of this potential was reminiscent of the late phase of the control LLD and was therefore presumably mediated through $\mathrm{GABA}_{\mathrm{B}}$ receptors that are not sensitive to BMI (Dutar and Nicoll, 1988). If synaptic transmission were participating in the coupling of interneurons in the different areas of the slice, these data would suggest that it also involved $\mathrm{GABA}_{\mathrm{B}}$ receptors.

The involvement of some other putative neurotransmitters such as adenosine, $\mathrm{ACh}$, noradrenaline, histamine, glycine, and opiates, whose effects have been previously identified in the hippocampus, was also investigated by the use of specific antagonists. As summarized in Figure $9 C$, none of these antagonists produced significant changes in LLD frequency, nor, moreover, was the propagation of LLDs affected in the presence of these antagonists (not shown).

\section{Discussion}

\section{4-AP and epileptiform activity}

We have found that 4-AP induces spontancous intcrictal-likc, epileptiform activity that originates in CA3 and propagates to the CA1 area along the Schaffer collaterals. In the adult rat hippocampus, 4-AP-induced epileptiform activity has previously been described in CA3 (Voskyul and Albus, 1985; Rutecki et al., 1987; Perreault and Avoli, 1991). Concerning the CA1 region, two studies have reported the occurrence of spontaneous and evoked bursts (Voskyul and Albus, 1985; Holsheimer and Lopes da Silva, 1989), whereas three others have described a potentiation of synaptic transmission without any evoked or spontaneous bursts (Buckle and Haas, 1982; Segal, 1987; Perreault and Avoli, 1989). The results reported here indicate that some of these discrepancies might be due to technical factors. For example, when compared to our previous findings (Perreault and Avoli, 1989), the modified slicing procedure in the present study resulted in the occurrence of interictal events in the CA1 area. These observations emphasize, therefore, the importance of considering the physiological status of the entire hippocampal slice even when investigations are carried out in one particular region. This is even more important for studies on experimental models of epilepsy in which the integrity of the CA3 area is pivotal in triggering epileptiform activity in other hippocampal areas (Wong and Traub, 1983).

Field discharges in CA1, as opposed to CA3, were not correlated intracellularly with bursts of action potentials. This is probably due to the fact that only a small number of CA1 neurons fired synchronously during each event, as indicated by the relatively low amplitude of the population spikes on the CA1 field bursts. Hence, the probability of finding neurons generating bursts of action potentials during each epileptiform event remained relatively low. Despite the presence of field potential discharges, single stimulation of the Schaffer collaterals failed in $80 \%$ of the slices to evoke bursts in the CA1 region. However, a brief train of low-intensity stimulation was capable of producing a small epileptiform burst identical to spontaneously occurring interictal events. Presumably, the facilitation of GABAergic inhibition (Buckle and Haas, 1982; Perreault and Avoli, 
A
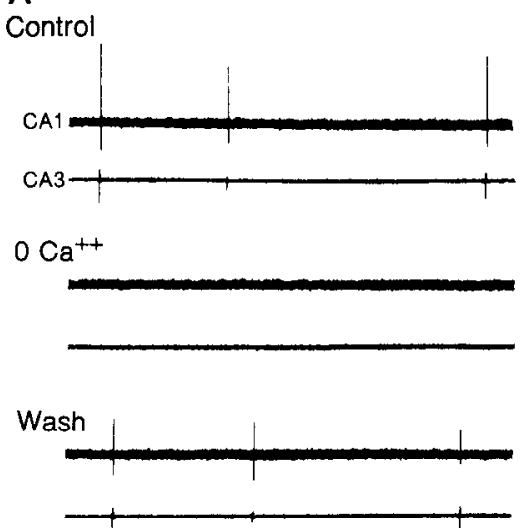

B

Control

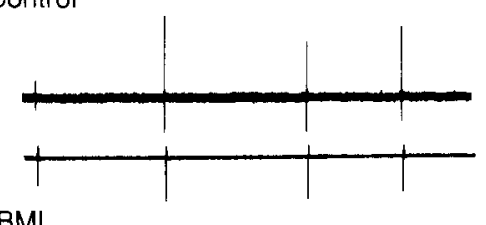

BMI

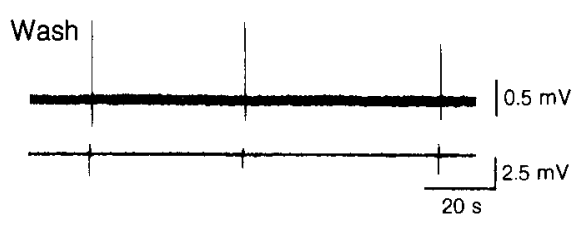

Figure 9. Effects of $0 \mathrm{Ca}^{2+}$ medium and various receptor antagonists on the occurrence of LLDs in slices where glutamatergic synapses were blocked. $A$, The top traces show low-speed chart records of LLDs occurring simultaneously in the CA1 and CA3 s. pyramidale of a slice where CNQX $(20 \mu \mathrm{M})$ and CPP $(5 \mu \mathrm{M})$ were also present in addition to 4-AP. When $\mathrm{Ca}^{2+}$ was removed from the medium (middle), LLDs were abolished and later reappeared after $\mathrm{Ca}^{2+}$ reintroduction (bottom). $B$, The top traces show the LLDs recorded in $C A 1$ and $C A 3$ in a medium similar to the one in control traces in $A$. After the addition of BMI $(50 \mu \mathrm{M})$, all activity disappeared (middle) and recovered after BMI washout (bottom). $C$, Graph shows effects of various receptor antagonists on the frequency of occurrence of LLDs. Only $\mathrm{Ca}^{2+}$ and BMI were effective in blocking the potential ( $p<$ 0.01 ). Calibration in $B$ applies to $A$.
C

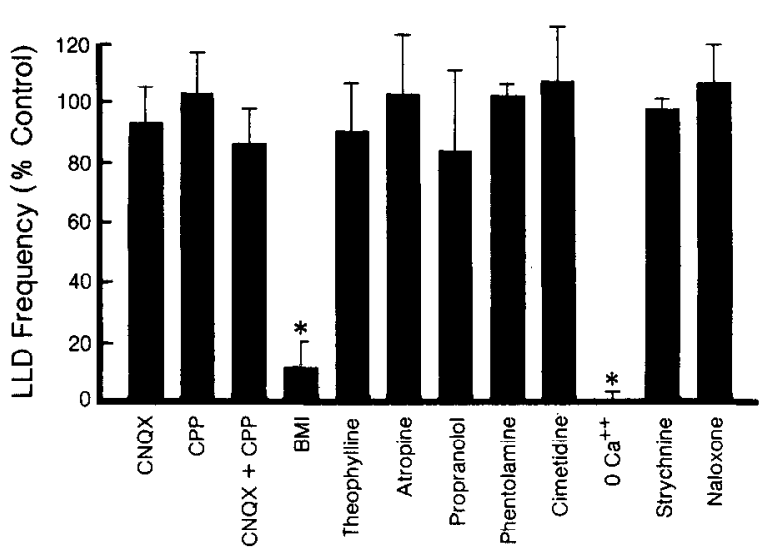

1989) combined with the lack of strong recurrent excitation (Knowles and Schwartzkroin, 1981; Christian and Dudek, 1988) prevents the generation of additional population spikes in CA1 following single shock stimulations of the afferent fibers.

\section{4-AP and GABA-mediated ILDS}

A less usual type of spontaneous, synchronous activity induced by 4-AP consisted of LLDs that occurred at a lower rate than the interictal discharges and were generated simultaneously in all hippocampal areas. This type of activity has already been described for the CA1 region, where it is caused by the activation of $\mathrm{GABA}_{\mathrm{A}}$ receptors located on dendrites (Perreault and Avoli, 1989). The LLDs recorded in CA3 and dentate neurons were also blocked by the $\mathrm{GABA}_{\mathrm{A}}$ antagonist $\mathrm{BMI}$ and displayed properties that were very similar to the LLDs recorded in CA1. Our observations therefore indicate that, in all areas, GABA released periodically from interneurons activates postsynaptic $\mathrm{GABA}_{\mathrm{A}}$ receptors that are presumably located in the dendrites, thereby producing a response whose hallmark is an LLD of both pyramidal and granule cells. The other GABA receptors appear also to be involved in the spontaneous LLDs, including somatic $\mathrm{GABA}_{\mathrm{A}}$ receptors, responsible for the initial hyperpolarization that usually precedes the $\mathrm{LLD}$, and $\mathrm{GABA}_{\mathrm{B}}$ receptors that generate the late hyperpolarizing phase of the potential (Perreault and Avoli, 1989). A similar potential has also been shown in 4-AP-treated slices of the neostriatum (Kita et al., 1985) and, more recently, in slices of the rat (Aram et al., 1991) and human neocortex (Avoli et al., 1988). The LLD described here is also reminiscent of the type II spontaneous field potential described by Voskyul and Albus (1985), who studied the effects of 4-AP in the hippocampal slice.

One feature of the LLD was the occurrence in all regions of action potentials near its onset, usually on the peak of the early IPSP or on the initial part of the LLD's rising phase. Evidence obtained in CAl cells had shown that these action potentials were generated ectopically by the axons of pyramidal cells (Perreault and Avoli, 1989). Interestingly, excitatory amino acid antagonists had no effect on the occurrence of these action potentials, indicating that they were not dependent on the function of glutamatergic synapses. One possibility is that the axonal regions of pyramidal cells are depolarized to threshold for action potential generation by a local rise in $\left[\mathrm{K}^{+}\right]_{o}$ presumably due to the opening of repolarizing $\mathrm{K}^{+}$channels in the interneurons that are firing during the LLD (see below). The blockage of axonal $\mathrm{K}^{+}$current(s) by 4-AP could further raise the level of excitability of the axon terminals (Kocsis, 1986).

Simultaneous recordings in the slice's three main areas as well as sectioning experiments indicate that the pacemaker of the LLD was not confined to a single region of the hippocampus but rather could be located in either the CA1, CA3, or dentate areas. Furthermore, once initiated in a given area, LLDs did not spread to the others in a constant or predictable pattern, suggesting that many alternative propagation pathways could be utilized. Finally, the results obtained with the sectioning experiments demonstrate that the integrity of the fibers connecting the different areas of the hippocampus is not necessary 
for LLD propagation. For instance, LLDs remained coupled between $\mathrm{CA} 1$ and dentate even following a complete sectioning of CA3 from the CA1-dentate regions. Although direct anatomical connections between $\mathrm{CA} 1$ and dentate cells are absent (Lorente de Nó, 1934), GABAergic interneurons located in the s. lacunosum-moleculare in CA1 send both axonal and dendritic branches across the fissure, toward the dentate granule cell layer (Lacaille and Schwartzkroin, 1988a). The unique properties of these interneurons could thus provide an anatomical substrate for the coupling of the LLDs in the two areas. However, the relatively slow propagation velocity observed $(0.004-0.017$ $\mathrm{m} / \mathrm{sec}$ ) suggests that alternative nonsynaptic mechanisms are more likely to be involved. This is supported by the fact that LLDs remained coupled in all areas of the slice after the addition of both NMDA and non-NMDA antagonists that block fast synaptic transmission of many pathways in the hippocampus (Neumann et al., 1988; Davies and Collingridge, 1989; Lambert et al., 1989). Recent observations in the neocortex have also shown that the occurrence of GABA-mediated slow depolarizations is resistant to excitatory amino acid antagonists (Aram et al., 1991).

It is likely, however, that in the intact slice, most of the LLD did propagate by making use of the well-known anatomical paths. For example, the propagation velocity of at least $34 \%$ of the LLDs traveling between CA1 and CA3 was within the range reported for the Schaffer collateral fibers (Andersen et al., 1978; Holsheimer and Lopes da Silva, 1989). Also, current sourcedensity analysis of the CA1 LLD has indicated that spontaneous LLDs in this area are initiated by an input traveling along the Schaffer collaterals (Perreault and Avoli, 1989). Alternative pathways might be utilized only when these connections were anatomically or functionally disrupted during the various experimental conditions employed here. Accordingly, the mean propagation velocity of LLDs spreading between CA1 and CA3 decreased in a similar manner after section of the Schaffer collaterals or in the presence of excitatory amino acid antagonists.

Synaptic transmission was required for the occurrence of LLDs because their appearance was abolished in $0 \mathrm{Ca}^{2+}$ medium or after the addition of $\mathrm{Cd}^{2+}$. These data, however, do not allow one to draw any conclusion concerning the propagation mechanism since the release of GABA from the interneurons is presumably $\mathrm{Ca}^{2+}$ dependent as well. Moreover, the antagonists of a variety of transmitter receptors had no effect on the generation of LIDs, indicating that none of the considered putative transmitters were involved in the initiation and propagation of this activity. Although there are many other transmitter candidates that were not assessed in this study, the occurrence of LLDs was suppressed after the addition of BMI on slices where synaptic transmission at glutamatergic synapses had previously been blocked by the application of antagonists for both NMDA and non-NMDA receptors. It is likely, therefore, that the only synchronous activity that occurred under these circumstances was the GABA-mediated LLD generated in pyramidal or granule cells. LLDs recorded intracellularly during these experiments were initiated by a brief hyperpolarization, presumably an IPSP, which would confirm the fact that LLDs are not initiated by any excitatory input, unless this input impinges exclusively on the interneurons. It could also be that interneurons are interconnected and excite one another by using GABA as a transmitter or other peptides that often colocalize with GABA in these cells such as somatostatin (Somogyi et al., 1984), enkephalin (Gall et al., 1981), or cholecystokinin (Greenwood et al.,
1981; Somogyi et al., 1984). However, electrophysiological evidence for direct interaction between interneurons indicates that this is inhibitory (Misgeld and Frotscher, 1986; Lacaille et al., 1987; Lacaille and Schwartzkroin, 1988a,b), although this situation might be different when the amount of GABA released by inhibitory interneurons is increased by $4-\mathrm{AP}$.

\section{Mechanisms involved in the coupling of interneurons}

One of the main findings of this study is that GABAergic interneurons located in different areas of the hippocampus interact by a mechanism that does not require excitatory synaptic transmission. The observations reported here might also suggest a simple model whereby LLDs are initiated by interneurons located in any region of the hippocampus and propagate following the recruitment of other interneurons located nearby and in other regions through the spatial dispersion of $\mathrm{K}^{+}$. According to this hypothesis, the firing of one interneuron will activate intrinsic repolarizing $\mathrm{K}^{+}$conductances, thereby producing a local rise in $\left[\mathrm{K}^{+}\right]_{o}$, which will be, at least in part, dispersed by diffusion and by spatial buffering through the glial cell syncytium (Somjen, 1984). The elevated $\left[\mathrm{K}^{+}\right]_{0}$ will depolarize neighboring interneurons and enhance their excitability (Hounsgaard and Nicholson, 1983; Balestrino et al., 1986). The activity of these other cells will act as a positive feedback to promote further $\left[\mathrm{K}^{+}\right]_{o}$ accumulation and dispersion and thus the firing of additional interneurons. This effect might be further facilitated by the lack of spike frequency adaptation in these cells (Schwartzkroin and Mathers, 1978; Lacaille and Schwartzkroin, 1988a,b). GABA-mediated potentials would be recorded in CA 3 and CA1 pyramidal cells as well as in dentate granule cells as the wave of $\mathrm{K}^{+}$spreads through the tissue.

We also propose that an increase in intrinsic interneuronal excitability (Segal, 1987) combined perhaps with a facilitation of GABA release at the synapse between the interneurons and the pyramidal (Buckle and Haas, 1982) and granule cells might also contribute to LLD generation by further promoting the spillover of GABA on the extrasynaptic receptors where the depolarizing response is presumably generated (Alger and $\mathrm{Ni}$ coll, 1982). The increased firing rate of the interneurons and the accumulation of $\left[\mathrm{K}^{+}\right]_{\text {o }}$ would therefore be linked in a positive fecdback loop (Hounsgaard and Nicholson, 1983) where 4- $\Lambda \mathrm{P}$ effects on the excitability of neurons will act as a reinforcing mechanism to promote their further discharge and the accumulation of $\left[\mathrm{K}^{+}\right]_{0}$. The $\mathrm{K}^{+}$accumulation hypothesis that we are proposing is supported by preliminary data indicating that LLD occurrence is associated with prolonged (10-30 sec) increases in $\left[\mathrm{K}^{+}\right]_{o}$ of up to $6 \mathrm{~mm}$ (P. Perreault, C. Drapeau, and M. Avoli, unpublished observations).

The role of $\mathrm{K}^{+}$accumulation as a nonsynaptic propagation mechanism has also been suggested previously to explain the spread of seizure-like activity occurring in low- $\mathrm{Ca}^{2+}$ solutions (Haas and Jefferys, 1984; Konnerth et al., 1986; Yaari et al., 1986). Interestingly, the range of propagation velocities reported for the low-Ca ${ }^{2+}$ bursts $[0.001-0.1 \mathrm{~m} / \mathrm{sec}$ (Haas and Jefferys, 1984), 0.2-0.5 mm/sec (Konnerth et al., 1986)] was lower than the LLD propagation velocity recorded in intact slices, but closer to the velocities estimated between $\mathrm{CA} 3$ and CA1 when NMDA and non-NMDA receptors were blocked $(0.02-0.2 \mathrm{~m} / \mathrm{sec})$ or between dentate and CA1 areas when the CA3 area was sectioned $(0.004-0.017 \mathrm{~m} / \mathrm{sec})$. Specific interactions between neighboring neurons attributed to $\left[\mathrm{K}^{+}\right]_{o}$ accumulation have also been 
reported in other preparations (Alkon and Grossman, 1978; Malenka et al., 1981; Yarom and Spira, 1982).

In principle, there are two additional nonsynaptic mechanisms, electrotonic coupling via gap junctions and ephaptic effects, that could facilitate the recruitment and the synchronization of firing of GABAergic interneurons locally. Electron microscopic observations have revealed the existence of gap junctions between various interneurons in the CA1, CA3, and dentate areas (Kosaka, 1983a,b); this type of coupling could therefore facilitate the synchronization of activity between these cells. Electrical field (ephaptic) effects are, however, unlikely to play any significant role here because interneurons are rather sparsely distributed in most regions of the hippocampus (Ribak et al., 1978) and therefore are not close enough to one another to be sensitive to the extracellular field generated by other interneurons (cf. Haas and Jefferys, 1984; Taylor and Dudek, 1984).

What triggers the firing of the leading interneuron, and thus initiates the whole cycle in the hippocampal slice treated with 4-AP, is not clear. One possibility is that 4-AP might produce a membrane instability that allows interneurons to depolarize spontaneously. Segal (1987) has indeed shown that 4-AP applied focally in the CAl area induces repetitive firing in intracellularly recorded interneurons and postulated that this activity could be responsible for the periodic appearance in pyramidal neurons of GABA-mediated hyperpolarizations. The propensity of the interneurons to undergo this kind of activity might therefore determine the frequency of occurrence of the LLDs reported in this study.

\section{References}

Alger BE (1984) Hippocampus: electrophysiological studies of epileptiform activity in vitro. In: Brain slices (Dingledine R, ed), pp 155199. New York: Plenum.

Alger BE, Nicoll RA (1982) Pharmacological evidence for two kinds of GABA receptors on rat hippocampal cells studied in vitro. J Physiol (Lond) 328:125-141.

Alkon DL, Grossman Y (1978) Evidence for non-synaptic neuronal interaction. J Neurophysiol 41:640-653.

Andersen P, Silfvenius H, Sunberg SH, Sveen O, Wingström H (1978) Functional characteristics of unmyelinated fibres in the hippocampal cortex. Brain Res 144:11-18.

Aram JA, Michaelson HB, Wong RKS (1991) Synchronized GABAergic IPSPs recorded in the neocortex after blockade of synaptic transmission mediated by excitatory amino acids. J Neurophysiol 65 : 1034-1041.

Avoli M (1990) Epileptiform discharges and a synchronous GABAergic potential induced by 4-aminopyridine in the rat immature hippocampus. Neurosci Lett 117:93-98.

Avoli M, Perreault P, Olivier $\Lambda$, Villemure J-G (1988) 4-Aminopyridine induces a long-lasting depolarizing GABAergic potential in human neocortical and hippocampal neurons maintained in vitro. Neurosci Lett 94:327-332.

Balestrino M, Aitkin P, Somjen G (1986) The effects of moderate changes of $\mathrm{K}^{+}$and $\mathrm{Ca}^{2+}$ on synaptic and neural function in the CA1 region of the rat hippocampal slice. Brain Res 377:229-239.

Buckle PJ, Haas HL (1982) Enhancement of synaptic transmission by 4-aminopyridine in hippocampal slices of the rat. J Physiol (Lond) 326:109-122.

Chestnut TJ, Swann JW (1988) Epileptiform activity induced by 4-aminopyridine in immature hippocampus. Epilepsy Res 2:187195.

Christian EP, Dudek FE (1988) Characteristics of local excitatory circuits studied with glutamate microapplication in the CA3 arca of rat hippocampal slices. J Neurophysiol 59:90-109.

Davies SN, Collingridge GL (1989) Role of excitatory amino acid receptors in synaptic transmission in area CA1 of rat hippocampus. Proc R Soc Lond [Biol] 236:373-384.
Dutar P, Nicoll RA (1988) A physiological role for $\mathrm{GABA}_{\mathrm{B}}$ receptors in the central nervous system. Nature 332:156-158.

Gall C, Brecha N, Karten HJ, Chang KJ (1981) Localization of enkephalin-like immunoreactivity to identified axonal and neuronal populations of rat hippocampus. J Comp Neurol 198:335-350.

Greenwood RS, Godar SE, Reaves TA, Hayward JN (1981) Cholecystokinin in hippocampal pathways. J Comp Neurol 202:335-350.

Haas H, Jefferys JGR (1984) Low-calcium field bursts discharges of CAl pyramidal neurones in rat hippocampal slices. J Physiol (Lond) 354:185-201

Holsheimer J, Lopes da Silva FH (1989) Propagation velocity of epileptiform activity in the hippocampus. Exp Brain Res 77:69-78.

Honoré T, Davies SN, Drejer J, Fletcher EJ, Jacobson P, Lodge D, Neilsen FE (1988) Quinoxalinediones: potent competitive nonNMDA glutamate receptor antagonists. Science 241:701-703.

Hounsgaard J, Nicholson C (1983) Potassium accumulation around individual Purkinje cells in cerebellar slices of the guinea pig. J Physiol (Lond) 340:359-338.

Kita T, Kita H, Kitai ST (1985) Effects of 4-aminopyridine (4-AP) on rat neostriatal neurones in an in vitro slice preparation. Brain Res 361:10-18.

Knowles WD, Schwartzkroin PA (1981) Local circuit synaptic interactions in hippocampal brain slice. J Neurosci 1:318-322.

Kocsis J (1986) Functional characteristics of potassium channels of normal and pathological mammalian axons. In: Ion channels in neural membranes (Ritchie JM, Keynes RD, Bolis L, eds), pp 122-144. New York: Liss.

Konnerth A, Heinemann U, Yaari Y (1986) Nonsynaptic epileptogenesis in the mammalian hippocampus in vitro. I. Development of seizurelike activity in low extracellular calcium. J Neurophysiol 56: 409-423.

Kosaka T (1983a) Gap junctions between nonpyramidal cell dendrites in the rat hippocampus (CA1 and CA3 regions). Brain Res 271:157161.

Kosaka T (1983b) Neuronal gap junctions in the polymorph layer of the rat dentate gyrus. Brain Res 277:347-351.

Lacaille JC, Schwartzkroin PA (1988a) Stratum lacunosum-moleculare interneurons of hippocampal CAl region. I. Intracellular response characteristics, synaptic responses, and morphology. J Neurosci 8: 1400-1410.

Lacaille JC, Schwartzkroin PA (1988b) Stratum lacunosum-moleculare interneurons of hippocampal CA1 region. II. Intrasomatic and intradendritic recordings of local circuit synaptic interactions. J Ncurosci 8:1411-1424.

Lacaille JC, Mueller AL, Kunkel DD, Schwartzkroin PA (1987) Local circuit interactions between oriens/alveus interneurons and CA1 pyramidal cells in hippocampal slices: electrophysiology and morphology. J Neurosci 7:1979-1993.

Lambert JDC, Jones RSG, Andreasen M, Jensen MS, Heinemann U (1989) The role of excitatory amino acids in synaptic transmission in the hippocampus. Comp Biochem Physiol 93A:195-201.

Lorente de Nó R (1934) Studies on the structure of the cerebral cortex. II. Continuation of the study of the ammonic system. J Psychol Neurol (Leipzig) 46:113-177.

Malenka RC, Kocsis JD, Ransom BR, Waxman SG (1981) Modulation of parallel fiber excitability by postsynaptically mediated changes in cxtraccllular potassium. Science 214:339-341.

Mihaly A, Bencsik K, Solymon T (1990) Naltrexone potentiates 4-aminopyridine seizures in the rat. J Neural Transm 79:59-67.

Misgeld U, Frotscher M (1986) Post-synaptic-GABAergic inhibition of non-pyramidal neurons in the guinea pig hippocampus. Neuroscience 19:193-206.

Neumann RS, Ben-Ari Y, Gho M, Cherubini E (1988) Blockade of excitatory synaptic transmission by 6-cyano-7-nitroquinoxaline-2,3 dione (CNQX) in the hippocampus in vitro. Neurosci Lett 92:64-68.

Perreault P, Avoli M (1987) Effects of 4-AP on CA3 and dentate neurons of rat hippocampal slices. Soc Neurosci Abstr 13:1160.

Perreault P, Avoli M (1989) Effects of low concentrations of 4-aminopyridine of CA1 pyramidal cells of the hippocampus. J Neurophysiol 61:953-970.

Perreault P, Avoli M (1991) Physiology and pharmacology of epileptiform activity induced by 4-aminopyridine in rat hippocampal slices. J Neurophysiol 65:771-785.

Ribak CE, Vaughn JE, Saito K (1978) Immunocytochemical localization of glutamic acid decarboxylase in neuronal somata following 
colchicine inhibition of axonal transport. Brain Res 140:315-322.

Rutecki PA, Lebeda FJ, Johnston D (1987) 4-Aminopyridine produces epileptiform activity in hippocampus and enhances synaptic excitation and inhibition. J Neurophysiol 57:1911-1924.

Schwartzkroin PA, Mathers LH (1978) Physiological and morphological identification of a nonpyramidal hippocampal cell type. Brain Res 157:1-10.

Segal M (1987) Repetitive inhibitory postsynaptic potential evoked by 4-aminopyridine in hippocampal neurons in vitro. Brain Res 414 : 285-293.

Somjen GG (1984) Interstitial ion concentration and the role of neuroglia in seizures. In: Electrophysiology of epilepsy (Schwartzkroin PA, Wheal H, eds), pp 304-341. London: Academic.

Somogyi P, Hodgson AJ, Smith AD, Nunzi MG, Gario A, Wu JY (1984) Different populations of GABAergic neurons in the visual cortex and hippocampus of cat contain somatostatin- or cholecystokinin-immunoreactive material. J Neurosci 4:2590-2603.

Spyker DA, Lynch C, Shabanowitz J, Jinn J (1980) Poisoning with 4-aminopyridine: report of three cases. Clin Toxicol 16:487-497.
Szente M, Baranyi A (1987) Mechanism of aminopyridine-induced ictal seizure activity in the cat neocortex. Brain Res 413:368-373.

Taylor CP, Dudek FF (1984) Excitation of hippocampal pyramidal cells by an electrical field effect. J Neurophysiol 52:126-142.

Thesleff S (1980) Aminopyridines and synaptic transmission. Neuroscience 5:1413-1419.

Voskyul RA, Albus H (1985) Spontaneous epileptiform discharges in hippocampal slices induced by 4-aminopyridine. Brain Res 342:5466.

Wong RKS, Traub RD (1983) Synchronized burst discharge in disinhibited hippocampal slice. I. Initiation in CA2-CA3 region. J Neurophysiol 49:442-458.

Yaari Y, Konnerth A, Heinemann U (1986) Non-synaptic epileptogenesis in the mammalian hippocampus in vitro. II. Role of extracellular potassium. J Neurophysiol 56:424-438.

Yarom Y, Spira ME (1982) Extracellular potassium ions mediate specific neuronal interaction. Science 216:80-82. 